\title{
FEDERATION OF EUROPEAN BIOCHEMICAL SOCIETIES
}

\author{
By D. J. R. VILLANUEVA \\ Instituto de Biologia Celular, C.S.I.C., Madrid
}

Tintertion HE Federation of European Biochemical Societies was founded in 1964 to promote contacts and the interchange of information between European biochemists. It now comprises twenty-one Societies. Much of the work of the Federation is concentrated on a comparatively fow clear-cut projects including organization of meetings and courses in advanced research techniques. Meetings are held every year at some centre of research where symposia are held and a number of papers dealing with the most recent research topics are delivered. Two meetings have boen organized; the first in London in 1964 and the second in Vienna in 1965. The third Federation meeting will be held in Warsaw in April 1966.

Organized by the Société Belge de Biochimie, the first summer course of the Federation of European Biochemical Societies was held at the Catholic University of Louvain during June 8-18; the subject was "Centrifugal Fractionation of Animal Cells: Theoretical Basis and Practical Procedures". The course, which was organized in detail by the Department of Physiological Chemistry, Institute of Physiology, gave a very wide view of the problem through lectures and practical demonstrations. It was sponsored by the Federation of European Biochemical Societies and the International Cell Research Organization of Unesco, which provided grants covering half the expenses of all the participants, who numbered about 20 and represented more than 15 nationalities; the places had been selected from a large number of applications. English was the official language of the course.

To comment on the importance of selecting the topic of separation of macromolecules and particles, it should be remembered that it is significant that some of the most remarkable recent advances in biochemistry have depended on new and improved separation procedures. Findings on the behaviour of a component in a soparation process dependent, for example, on sedimentation velocity, provide a convenient basis for preliminary quantitative characterization. If such work is done systematically in correlation with investigations of biochemical function and with electron microscopy studies it may provide very interesting information which would have been difficult to obtain by other means.

Prof. C. de Duve (Department of Physiological Chemistry, University of Louvain, and Rockefeller Institute, New York) was the chairman of the course. Specialists will not need to be told that the science of centrifugation has made considerable progress during the past decade and that the Louvain group has made important contributions in this field.

Prof. de Duve described the general principles of centrifugal fractionation, theory of sedimentation, analysis of sub-cellular fractions, differential centrifugation in homogeneous medium, density gradient, isopycnic centrifuga. tion, and the calculation, presentation and interpretation of results. Prof. J. Berthet (Department of Physiological Chemistry, Louvain), who was responsible for the internal and scientific organization of the course, together with Drs. H. Beaufay and P. Jacques, gave lectures on homogenization, centrifugation equipment, density gradiont contrifugation, practical procedures, density gradient differential centrifugation and density gradient centrifugation for analysis of macromolecules. Prof. Drochmans (Department of Experimental Cytology, Institut Bordet, University of Brussels) gave a lecture and practical demonstration of the preparation of particulate glycogen; Dr. D. B. Roodyn (Department of Biochemistry, University College, London) described methods of preparing nuclej, and Prof. E. Schram (Department of Animal
Morphology, University of Brussels) gave a lecture on density gradient differential centrifugation and analysis of ribosomes and polysomes, followed by a very fascinating demonstration.

Practical experiments and demonstrations were also supervised by Profs. Berthet and H. Beaufay, Drs. P. Jacques, A. Trouet, G. Vaes, M. Robb and Thinès-Sempoux (Department of Physiological Chemistry of Louvain), Drs. A. Burny, G. Huez and G. Marbaix (Department of Biological Chemistry, University of Brussels) and Prof. R. Wattiaux (Department of Physiological Chemistry, Namur), and took place in the laboratories of the Department of Physiological Chemistry of the Institute of Physiology. Fundamentally, the practical work comprised the preparation of gradients and a general but very detailed survey of the techniques of centrifugal fractiona. tion, in which cells were disrupted in a homogenizer and then spun in a centrifuge at successively higher speeds to yield a number of fractions containing organelles of different types. The organelles were then explored by means of biochemical methods determining the association of a number of enzymes with the cellular structures. The importance of this systematized technique has been dramatically emphasized in recent years by the isolation of a new cell organelle, the lysosome, which has already been shown to have fundamental importance for cell biology.

The organization of the course was well carried out. Equipment was of a high order and very specialized, and a team of expert assistants helped so that participants were able to obtain the maximum advantage. This report would be incomplete without recording the appreciation of the participants for the excellent arrangements made by Prof. H. G. Hers, who assumed the administrative responsibility of the course with meticulous attention to detail, and for the hospitality extended to them.

Mention must be made of the enthusiasm of Prof. C. Liébecq, secretary of the Société Belge de Biochimie in persuading Prof. de Duve to start a new line for the Federation of European Biochemical Societies with this course and in particular for the Society's ready willingness at all times to co-operate with the scientific staff and participants in providing the required facilities.

To sum up the course, Prof. C. de Duve's group attempted in the lectures and practical work to draw an overall and consistent picture of the succession of processes constituting a mechanism of separation of sub-cellular particles. The participants of the course were given every facility to appreciate the methods developed by these skilled specialists, and the progress which can result from detailed analysis of the enzymatic properties of sub-cellular particles separated by differential and density gradient centrifugation and from the characterization of the various particles. The course, which was much appreciated by those present, ended with a general discussion of the practical results.

This first summer school of the Federation brought together biochemists of many different specialities. Throughout the course an atmosphere of the greatest cordiality and friendship prevailed. Many problems of common interest were discussod, and evening meals at the Faculty Club of the University, a beautiful and modern building, kept members gathered together after the laboratory work. The course in fact performed two interesting functions: one European and the other scientific. An official dinner was held on June 11, and presided over by Prof. C. de Duve. A succossion of national toasts was offered by the participants to the staff of the Depart. 
ment and the organizers, one representative of each country thanking in his own language the staff and all the people collaborating in the success of the course. In reply, Prof. de Duve thanked all the participants for their cooperation and expressed his satisfaction with the result of this first summer school ; he expressed the conviction that this would be the starting point for a series of similar courses for which interest was amply evident.

The Federation of European Biochemical Societies is to be congratulated on organizing courses of such quality.
The general nature of this kind of course will ensure its future success, and there is clearly no shortage of subjects. The importance of ensuring conditions that will facilitate free international co-operation and interchange in any field of scientific endeavour is not small, and the organization of this course is an important new landmark in the development of relations among scientists of different countries. We are sure that in the very near future similar meetings will be held in other biochemical institutes.

\section{BIOCHEMISTRY IN MAGDEBURG}

$\mathrm{W}$ E have recently returned from a short visit to East Germany, where we were invited, as guests of the G.D.R. Government, to participate in the second annual conference of the Biochemical Section of the Society for Experimental Medicine of the G.D.R. held at Magdeburg during June 24-26.

The conference was held at the Medical Academy in Magdeburg under the presidency of Prof. K. Lohmann. It was attended by about 300 biochemists, including a notable group from the Federal Republic of Germany and representatives of many countries of Eastern and Western Europe. Prof. Eberhard Hofmann, of Magdeburg, in his organization of the conference, followed the best traditions of international scientific meetings.

The meeting centred about three symposia: (a) "Functional Biochemistry of Cell Membranes and Mitochondria"; (b) "Problems of the Regulation of Glycolysis and Fermentation"; (c) "Aspects of the Training of Biochemists". There were also sessions where short communications were read. In all, about 100 papers wer $\Theta$ heard.

By far the most interesting event was the symposium on glycolysis and fermentation. This session, conducted admirably by Prof. H. Frunder, of Jena, was introduced by Prof. Benno Hess, Dortmund. In his exposition, Hess centred his arguments on mathematical models of glycolysis and on the oscillatory behaviour of metabolites under transitional conditions in living yeast and in yeast press juice. The importance of phosphofructokinase in regulatory mechanisms was emphasized in many contributions. Thus Hommes (Nijmegen) described a number of phosphofructokinases in different yeasts which were all inhibited by ATP. The phosphofructokinases from yeasts that showed an aperiodic change in pyridine nucleotide levels after anaerobiosis were activated by fructose-6-phosphate and not by AMP, while the enzymes from 'asymptotic' yeasts were activated by neither of these compounds. 'Oscillatory' yeasts had phosphofructokinases which were inhibited by ATP and activated by fructose-6-phosphate and AMP. Freyer and Kopperschläger (Magdeburg) suggested that the high aerobic glycolysis of ascites tumour cells could be explained by the insensitivity to ATP of the phosphofructokinase, together with the low pyruvate utilization and the limited power of the mitochondria to oxidize cytoplasmic NADH. The inhibition of glycolysis in ascites tumour cells by alkylating cytostatic agents appears to be due to an activation of NAD-splitting enzymes (Grunicke, Richter and Holzer, Freiburg). Lamprecht (Munich) discussed the regulation of glycolysis in human heart muscle. Rapoport (Berlin) considered the regulatory significance in erythrocytes of an NADP-dependent lactate dehydrogenase and, in ascites tumour cells, of a lactate oxidase not requiring a pyridine nucleotide.

In the symposium on the training of biochemists, we learned from Prof. Hofmann's introductory remarks that courses for biochemists in the Faculty of Science existed. in only two German universities: Tübingen in the West and the Humboldt University in East Berlin. Hofmann emphasized the need for additional courses of this kind. We had the opportunity of describing the existing courses in London and some of the proposed developments in Britain's now universities. Prof. Bücher (Munich) expressed enthusiasm for the relative brevity of degree courses in Britain and was joined by Prof. Rapoport (Humboldt University, Berlin) in a plea for the elimination of the time-consuming medical course as a prerequisite for a biochemical career in Germany. It was evident that these matters were of vital interest to the younger members of the conference.

We were impressed by the high quality of the scientific work as it was described in the communications and by the evident desire of our East German colleagues to improve their contacts with the countries of the West. It is deeply disturbing that the absurdities of politics make it difficult for us to contribute to this improvement and to make a full return for the hospitality which wo received.

D. F. Cheesman J. R. LAgNado

\section{INDUSTRIAL FEEDING AND CANTEEN MANAGEMENT}

\begin{abstract}
THE report on the joint symposium on "Industrial Feeding and Canteen Management in Europe", held in Rome during September 2-7, 1963, has now been published under the auspices of the Food and Agriculture Organization, the International Labour Organization, and the World Health Organization*. After explaining the reasons for the interest of these organizations in the subject, the report summarizes the situation to-day in various European countries and suggests some steps to

* Food and Agriculture Organization of the United Nations. FAO Nutrition Meetings Report Series, No. 36: Report of the Joint Symposium on Industrial Feeding and Canteen Management in Europe, Rome, Italy, 2-7 September, 1963. Pp. 44. (Rome: Food and Agriculture Organization of the United Natilins. London: H.M.S.O., 1965.) 2s. $6 d . ; 50$ cents.
\end{abstract}

be taken if these specialized agencies are to assist member countries to solve their more urgent problems.

In most European countries industrial feeding is regarded as an integral part of the facilities of the factory, even though the provision of food to workers is frequently not required by law. The determining factor in provision of a canteen and in the type of service offered is usually the demand and need of the workers. The use of canteen services varies in different countries and is often disappointingly small. The effect of nutrition on occupational health and on working efficiency and such matters as food supply, levels of food consumption and food habits, as well as the problems encountered in pro- 